\title{
Smoking among rural and urban young women in China
}

\author{
Michael G Ho, ${ }^{1}$ Shaojun $\mathrm{Ma}^{2}{ }^{2}$ Wanxing Chai, ${ }^{2}$ Wan Xia, ${ }^{2}$ Gonghuan Yang, ${ }^{3}$ \\ Thomas E Novotny ${ }^{4}$
}

${ }^{1}$ University of California, Los Angeles, California, USA ${ }^{2}$ Institute of Basic Medical Sciences, Chinese Academy of Medical Sciences and School of Basic Medicine, Peking Union Medical College, Beijing, China ${ }^{3}$ China Center for Disease Control and Prevention, Beijing, China ${ }^{4}$ San Diego State University, San Diego, California, USA

\section{Correspondence to}

Thomas E Novotny, Graduate School of Public Health, San Diego State University, Hardy Tower 119, 5500 Campanile Drive, San Diego, California 92186, USA; tnovotny@mail. sdsu.edu

Received 14 April 2009 Accepted 14 September 2009 Published Online First 11 October 2009

\section{ABSTRACT}

Methods A survey of 11095 urban and rural women attending high school or college, aged 14-24 years, in 6 Chinese provinces was conducted. Ever-smoking (ES), current smoking, established smoking and intention to smoke frequencies were calculated. Bivariate analyses were conducted to identify possible correlates of smoking, and those found to be significant at the $p=0.1$ level were included in a multivariate logistical regression model to obtain adjusted OR for correlates of ES.

Results ES prevalence was $20.1 \%$, with urban female students (UFS) at $22.0 \%$ and rural female students (RFS) at $19.0 \%(p<0.01)$. Established smoking prevalence was higher among UFS than RFS $(2.4 \%$ vs $0.9 \%, p<0.01)$.

Similarly, current smoking prevalence was higher among UFS than RFS $(4.2 \%$ vs $1.9 \%, p<0.01)$. The intention to smoke prevalence was higher among UFS than RFS $13.5 \%$ vs $1.7 \%, p<0.01)$. The majority were aware that smoking was harmful to health, but were less aware of specific diseases associated with smoking. ES was associated with awareness of cigarettes made for women (OR, 1.66, $95 \% \mathrm{Cl} 1.49$ to 1.86 ) and thinking that they were less harmful than other cigarettes (OR 1.54, 95\% Cl 1.33 to 1.79). The strongest correlate of ES was low refusal self-efficacy (OR 6.35, 95\% Cl 5.32 to 7.57).

Conclusions This is the first report that having heard of women's cigarettes is a correlate of smoking among young Chinese women. ES among young Chinese women has increased in the last decade, and thus, specific prevention strategies need to be developed to prevent the tobacco epidemic from spreading among this vulnerable population.

This large survey of young (14-24 years of age) school attending women in 6 provinces has identified some important correlates of smoking initiation among them. The majority of female students in China have been exposed to cigarettes made for women, and low refusal self-efficacy was the major correlate of ever-smoking among this vulnerable group. These data may serve to stimulate policies and educational programs that may be needed to prevent a potentially devastating future epidemic of smoking-attributable disease among women in China.

\section{INTRODUCTION}

China leads the globe in tobacco production and consumption. According to the 2008 World Health Organization's MPOWER Report on the Global Tobacco Epidemic, China produces over 2 million metric tons of tobacco leaf and manufactures over 1.5 trillion cigarette sticks annually. ${ }^{1}$ Chinese smokers consume on average 1771 cigarettes or 2021.8 billion total cigarettes annually, ${ }^{2}$ and China is now home to 350 million, or one-third, of the world's total smokers. ${ }^{1}{ }^{3}$ According to the 1996 national tobacco use survey, $66.9 \%$ of men and $4.2 \%$ of females aged 15-69 currently smoke. ${ }^{3}$

There are more than 650 million women living today in China, and the tobacco industry, Chinese and multinational, has targeted this demographic group through advertising and brand segmentation. ${ }^{4}$ Further, recent studies report experimentation rates among young women to be increasing. Among ninth graders in the China Seven Cities Study ${ }^{5}$ lifetime experimentation was found to be between 17.4 and 23.9\% in 2004; the 1998 national Adolescent survey of 24000 middle school youth found $12.8 \%$ experimentation among young girls. ${ }^{6}$ Some of this variability is due to different timing of the surveys, as well as different target populations and survey methodologies. In addition, $\mathrm{Ma}$ et $\mathrm{al}^{7}$ analysis of risks for experimentation using the China Seven Cities Study sample suggests that friends smoking and perceived smoking prevalence were predictive of experimentation.

Given the large population of women in China (over 650 million), concerns about an explosive tobacco use epidemic among them have arisen. Previous cultural norms have kept smoking among women at low levels, but China and the world are changing due to globalisation and urbanisation. Between 1978 and 2004, China's urban population rose from $17.9 \%$ to $41.8 \%$ of the total population, which is an increase from 170 million to 540 million people moving to urban areas. ${ }^{8}$ This phenomenon may add to behavioural risks for young women through stresses not found in rural areas and the social changes caused by urban migration. ${ }^{9}$ These changes are accompanied by China's 2001 entrance into the World Trade Organization (with likely commercial expansion of transnational tobacco companies (TTCs) in China) and clearly evident targeting strategies by TTCs towards young women.

Additional research is needed to understand demographic shifts and tobacco industry strategies that may increase the susceptibility to smoking initiation among young women in China. In 2006, we conducted a qualitative pilot study in Beijing to better understand the factors that may lead to a future increase in smoking prevalence among women in China. ${ }^{10}$ We found that many of the same driving forces for susceptible women in the USA in the 1950s (ie, smoking and its association with independence, lack of regulation of tobacco company advertisements, etc) are in fact now evident in China. Tobacco advertisements and unlocked scheme, see http // tobaccocontrol.bmj.com/site/ about/unlocked.xhtml. 
marketing are widely present in the form of tobacco companysponsored sporting and cultural events and cigarettes that are marketed specifically for women (CMFW). Characterised by their long, slim and colourful designs, CMFW brands such as '520' and 'More' were identified in our pilot study as two of the more popular CMFW brands. They were also noted to be easily purchasable from street vendors and large supermarkets. Finally, we found that women who smoke were thought to be more elegant and that the culture of smoking was deeply ingrained in Chinese social interactions. Because of these focus group findings, as well as the demographic changes, increased marketing pressures and the emergence of CMFW in China, additional understanding of behaviours, initiation potential, knowledge and attitudes about smoking among rural and urban young women is important. Such information may be helpful to public health professionals in developing appropriately targeted prevention strategies. This is increasingly important as China is a party to the Framework Convention on Tobacco Control and because of recent infusions of tobacco control funding from multiple sources such as the Bloomberg Global Initiative, the US National Institutes of Health, the China Medical Board of New York and others. Therefore, in 2008, we conducted a cross-sectional behavioural survey of urban and rural women students attending Chinese high school or college (ages 14-24) in six Chinese provinces.

\section{METHODS}

\section{Sampling frame}

Researchers at Peking Union Medical College (PUMC) and the China Centers for Disease Control and Prevention (CCDC) evaluated provinces in China as study sites based on current smoking rates, existing Provincial administrative and research connections, and available resources. The provinces were first evaluated by the level of current smoking using a scale of 1-4, with 1 as the highest quartile level of smoking and 4 as the lowest level (as reported in the 1996 Prevalence Survey.) Of China's 31 provinces, most (25) provinces report $<6 \%$ smoking prevalence among women (level 3-4), but we sought to include provinces with a wider range of smoking prevalence (table 1). ${ }^{11}$

Our six target provinces were then selected based upon tobacco epidemic level, geographical location, ability to achieve adequate sample size and technical capacity of the provincial CDCs (table 2). Our selected provincial capitals of Beijing, Changchun, Chongqing, Guangzhou, Lanzhou and Nanchang provide geographical representation to each of the six major population centres of China as defined by the National Population Census definition (North, Northeast, Southeast, South, Northwest, or East). ${ }^{8}$ We did not include any 'level 1' provinces (Liaoning or Shanxi) because their provincial CDC teams did not have the resources to conduct the survey at the time of our study.

\section{Inclusion and exclusion criteria}

Eligible participants were defined as those who were: (1) women with Chinese citizenship; (2) 14-24 years of age; and

Table 1 Level of tobacco epidemic (scored from 1-4) among women in Chinese provinces, 1996

\begin{tabular}{llc}
\hline $\begin{array}{l}\text { Quartile level of } \\
\text { tobacco epidemic } \\
\text { among females }\end{array}$ & $\begin{array}{l}\text { Current smoking } \\
\text { prevalence } \\
\text { among women, \% }\end{array}$ & $\begin{array}{l}\text { No. of } \\
\text { provinces }\end{array}$ \\
\hline 1 & 10.01 to 15.5 & 2 \\
2 & 6.01 to 10.00 & 4 \\
3 & 3.01 to 6.00 & 14 \\
4 & 0.4 to 3.00 & 11 \\
\hline
\end{tabular}

(3) attending high school or college during the time of the field study. We included only high school and college students based on our available financial resources and existing networks; we also considered the potential development of prevention programs through the school systems that could be based on our findings. Gross national enrolment in high schools reached $42.8 \%$ in 2002, up from $26.0 \%$ in 1990 , and the gross national enrolment in colleges reached $15.0 \%$ in 2002 , up from $3.4 \%$ in $1990 .{ }^{12}$ We excluded non-students from our survey, but other studies suggest that smoking rates among young working women may be even higher than those of students. ${ }^{13}$

Rural female students (RFS) and urban female students (UFS) were differentiated by self-reported rural versus urban hukou, or household registration. Historically, the hukou system was created in the 1950 s as a way to control migration in China. ${ }^{14}$ It now provides at least some indication of cultural affinity (rural vs urban) for the students selected for this survey.

\section{School cluster sampling}

Within each province, a two-stage stratified cluster sampling method was implemented. In the first stage, sampling was school based with stratification by type of school (regular high school, vocational/technical high school, 'key point' or elite high school, or university). We randomly selected one school within each of the three school types in the provincial capital to include in our sample. In the second stage, within each school, we randomly selected a specific number of classes to reach a respondent sample size of 200 in each school; this was primarily determined by resource availability. We purposively sampled students from rural and urban schools based on home town registration in order to survey roughly the same number of rural and urban students overall; this was not then a representative sample by region or province.

\section{Survey methods and measures}

The protocol used in this study received approval from the Institutional Review Boards at the University of California, San Francisco (UCSF) and PUMC. The survey instrument was developed collaboratively by researchers at UCSF and PUMC based on existing survey items from the CCDC (used in the National Prevalence Survey) and other sources. All survey items were developed in English, translated into Chinese, and then back-translated into English by translators fluent in both languages and with experience in tobacco control. This assured that questions were understood in the same way between research teams at UCSF and PUMC. Many of the new questions had been pretested in our focus groups, and many of the previously used questionnaire items had been used in the 1996 National Survey. The survey collected the following information: (1) socioeconomic and demographic data; (2) smokingrelated behaviours, including ever-smokers (ES), established smokers (ESTS), current smokers (CS), students who intended to smoke and never-smokers; (3) smoking environment and attitudes, including attitudes towards female smoking and smoking among celebrities; parental smoking and parental attitudes towards smoking; friend smoking and responses to being offered a cigarette (which assesses self-efficacy); (4) knowledge and attitudes towards CMFW, including knowledge and attitudes towards female brands and product promotion activities; (5) knowledge of health risks (we included a bogus question on health risks associated with smoking, asking whether smoking was associated with hepatitis, in order to validate subjects' reported knowledge of risks); and (6) attitudes towards antismoking policies. Previous studies have shown the cognitive 
Table 2 Target provinces, estimated school units and level of smoking among young women in selected Chinese provinces, 2008

\begin{tabular}{llllll}
\hline $\begin{array}{l}\text { Province name/ } \\
\text { Capital city }\end{array}$ & $\begin{array}{l}\text { Metropolitan } \\
\text { population (urban/ } \\
\text { rural), millions }\end{array}$ & $\begin{array}{l}\text { Estimated no. of } \\
\text { high schools at } \\
\text { metropolitan area }\end{array}$ & $\begin{array}{l}\text { Estimated no. } \\
\text { of colleges at } \\
\text { capital city }\end{array}$ & $\begin{array}{l}\text { Level of tobacco } \\
\text { epidemic among } \\
\text { females }\end{array}$ & $\begin{array}{l}\text { Geographical } \\
\text { location }\end{array}$ \\
\hline Beijing/Beijing & $7.8 / 3.4$ & 791 & 91 & 2 & North \\
Jilin/Changchun & $3.1 / 4.5$ & 389 & 28 & 2 & Northeast \\
Sichuan/Chongqing & $15.4 / 63.3$ & 154 & 20 & 3 & Southeast \\
Guangdong/Guangzhou & $23.9 / 51.8$ & 190 & 46 & 3 & South \\
Gansu/Lanzhou & $3.2 / 7.4$ & 229 & 14 & 4 & Northwest \\
Jiangxi/Nanchang & $9.8 / 32.3$ & 200 & 14 & 3 & East \\
\hline
\end{tabular}

factors such as those included in this survey, as well a reasoned behaviour theory-based measurements are important in predicting smoking among young Chinese subjects. ${ }^{15}$

An ES was defined as a respondent who answered yes to "Have you ever tried or experimented with cigarette smoking, even a few puffs?". Subjects were defined as ESTS if they answered yes to "Have you smoked 100 cigarettes in your life?". CS were defined as respondents who answered, "I have smoked everyday in the past 30 days" or "I have smoked in the past 30 days but have not smoked everyday" in response to "During the past 30 days, have you smoked cigarettes?". Never-smokers were defined as respondents who answered no to "Have you ever tried or experimented with cigarette smoking, even a few puffs?" and "Do you think you will try to smoke a cigarette in the next 6 months". A student with intention to smoke (IS) status was established by answering no to "Have you ever tried or experimented with cigarette smoking, even a few puffs?" and yes to "Do you think you will try to smoke a cigarette in the next 6 months". These categories were selected in order focus primarily on experimentation and IS; we are most interested in vulnerability and less interested in current smoking prevalence (which for our study includes smoking anytime in the last 30 days).

Team survey leaders were senior Provincial CDC public health officials who participated in a 3-day workshop to edit the draught questionnaire and to receive training on survey administration. Team survey leaders, survey administrators and local provincial educational bureau members visited each of the provincial high schools and universities to obtain permission to conduct the study. Potential subjects were then approached by survey administrators, who informed them of the voluntary nature of the study and who explained the purpose and process of the survey; verbal informed consent was obtained. Participants were assured of their anonymity by coding each survey without using names or personal identifiers. Surveys were administered to selected classes at each of the sites and took approximately $20 \mathrm{~min}$ to complete. A small gift (Beijing 2008 Olympic keychain souvenir worth about US\$1) was provided to participants as a gesture of thanks, according to Chinese custom. Edited surveys were faxed back to the CCDC offices in Beijing for data entry. In addition, we administered the survey to a repeat $10 \%$ sample of classes across the entire sample in order to make sure there was internal consistency of responses. The entire field study was completed between 16 May and 31 July 2008.

\section{Data analysis}

All statistical analyses were conducted using SAS 9.0 (SAS, Cary, North Carolina, USA). We computed frequencies (\%) of the sample characteristics including smoking status and each variable stratified by UFS or RFS. Since we did not intend our sample to be population representative, statistical adjustment for the cluster sampling technique was not performed. The $\chi^{2}$ test was applied to categorical variables to determine significant associations between correlates (age, province, pocket money spent per month, self-reported school performance, friend smoking, boyfriend smoking, parent reaction to smoking, attitude towards female smoking, exposure to CMFW, knowledge about CMFW and low refusal self-efficacy) and outcomes. Variables found to be significant in the bivariate analyses at the $p=0.1$ level were then included in a multivariate logistic model to develop adjusted OR for risk of smoking initiation. This model included rural/urban status, pocket money spent per month, selfreported school performance, friend smoking, boyfriend smoking, parent reaction to smoking, attitude towards female smoking, exposure to CMFW, knowledge about CMFW and low refusal self-efficacy. Multilevel responses were dichotomised for clarity of presentation, based on major break points in the scores. The model included adjustment for age, school type and province so that residual knowledge, attitude and behaviour elements could be specifically evaluated.

\section{RESULTS}

The total survey sample was 11095 (4920 RFS and 6175 UFS) representing a $94.9 \%$ participation rate from the target population. The non-response rate was similar for UFS (5.2\%) and RFS $(5.0 \%, p=0.79)$ (table 3). Similarly, the mean age, ethnicity and school performance were similar for RFS and UFS, but there were more universities represented in urban settings than in rural settings and more vocational training institutions in rural areas. Regarding pocket money spent monthly, $22.3 \%$ of UFS spent over $\$ 59$ per month, compared to only $10.2 \%$ of RFS who reported having this amount of pocket money $(p<0.01)$.

Overall, ES prevalence was $20.1 \%$, CS was $3.2 \%$, ESTS was $1.7 \%$ and IS was $2.7 \%$ (table 4 ). The ES, CS, ESTS and IS prevalence rates were all statistically higher among UFS than among RFS (table 4). Somewhat higher prevalence of smoking by RFS fathers was evident, but there was no difference for mother's smoking. A slightly higher percentage of UFS over RFS felt that female smokers were cooler than their female never-smoker counterparts. In addition, a slightly higher percentage of UFS than RFS linked female smoking to independence and charisma. Although, only $4.1 \%$ of RFS and $9.6 \%$ of UFS had tried CMFW, the overwhelming majority of RFS and UFS had heard of CMFW.

Most subjects had reasonable knowledge about the health risks of smoking, especially lung cancer, but less than two-thirds of UFS and RFS believed smoking increases risk for cardiovascular diseases (which constitutes about $33 \%$ of total mortality in China $\left.{ }^{16}\right)$. When questioned about smoking and hepatitis, more than two-thirds of UFS and RFS also believed smoking increases risk for this non-smoking-related disease. With regard to sources of health risk information about smoking, television seemed to be the most likely source $(76.7 \%$ overall), with slightly higher percentage for RFS. Most subjects were aware of China's tobacco 
Table 3 Sample demographics (\%), RFS and UFS, China, June 2008

\begin{tabular}{|c|c|c|c|}
\hline & Total & RFS & UFS \\
\hline Sample size & 11095 & 4920 & 6175 \\
\hline Mean age $\pm S D$ & $18.3 \pm 2.7$ & $18.3 \pm 3.4$ & $18.3 \pm 1.9$ \\
\hline Response rate (\%) & 94.9 & 95.0 & 94.8 \\
\hline \multicolumn{4}{|l|}{ Province/city (\%) } \\
\hline Beijing & 16.0 & 14.8 & 16.9 \\
\hline Changchun & 17.5 & 17.3 & 17.6 \\
\hline Chongqing & 17.0 & 22.0 & 13.1 \\
\hline Guangzhou & 16.5 & 10.5 & 21.3 \\
\hline Lanzhou & 16.7 & 19.1 & 14.9 \\
\hline Nanchang & 16.3 & 16.3 & 16.2 \\
\hline \multicolumn{4}{|l|}{ School classification (\%) } \\
\hline Vocational/technical HS & 22.0 & 28.8 & 16.6 \\
\hline Regular HS & 22.4 & 25.4 & 20.1 \\
\hline Key point HS & 23.0 & 19.3 & 25.9 \\
\hline University & 32.6 & 26.5 & 37.4 \\
\hline \multicolumn{4}{|c|}{ Self-reported school performance (\%) } \\
\hline Very good & 1.7 & 1.4 & 2.0 \\
\hline Good & 22.7 & 20.8 & 24.2 \\
\hline Fair & 67.5 & 69.6 & 65.8 \\
\hline Poor & 7.2 & 7.5 & 7.1 \\
\hline Very poor & 0.6 & 0.5 & 0.8 \\
\hline \multicolumn{4}{|l|}{ Ethnicity (\%) } \\
\hline Han Chinese & 95.2 & 96.4 & 94.3 \\
\hline Other (ie, minority) & 4.6 & 3.4 & 5.6 \\
\hline \multicolumn{4}{|c|}{ *Pocket money monthly (To nearest US\$) (\%) } \\
\hline Between 0-\$7 & 17.9 & 21.3 & 15.1 \\
\hline Between $\$ 8-\$ 14$ & 19.5 & 22.7 & 17.1 \\
\hline Between $\$ 15-\$ 29$ & 23.2 & 25.0 & 21.7 \\
\hline Between $\$ 30-\$ 58$ & 21.7 & 20.1 & 22.9 \\
\hline Between $\$ 59-\$ 117$ & 13.1 & 9.3 & 16.3 \\
\hline Over $\$ 118$ & 4.1 & 0.9 & 6.0 \\
\hline
\end{tabular}

*Pocket money spent per month by respondents was converted to US\$ based on the conversion $6.8 \mathrm{RMB}=\mathrm{US} \$ 1$ at the time of analysis.

HS, high school; RFS, rural female students; UFS, urban female students.

control policies, especially a law in China that prohibits selling cigarettes to minors (under age 18), and most were supportive of this law and a law banning advertisement of tobacco products.

For smoking by school type, urban vocational/technical high schools had significantly higher ES prevalence at 32.3\%, compared with $17.6 \%$ to $21.2 \%$ among all other school types (figure 1).

Bivariate comparisons of correlates of ES and the results of the stepwise multivariate analysis of these correlates are shown in table 5. After simultaneous adjustment for correlates at the
Table 4 Smoking behaviour, attitudes, knowledge, health risk knowledge (\%) among RFS and UFS, China, 2008

\begin{tabular}{|c|c|c|c|c|}
\hline & Total & RFS & UFS & p Values* \\
\hline Sample size & $\mathrm{N}=11095$ & $\mathrm{~N}=4920$ & $\mathrm{~N}=6175$ & \\
\hline \multicolumn{5}{|l|}{ Smoking behaviour (\%) } \\
\hline Ever-smoker & $20.1 \%$ & $19.0 \%$ & $22.0 \%$ & $<0.01$ \\
\hline Mean age first puff & $\begin{array}{l}12.7 \pm \\
4.3 \text { years }\end{array}$ & $\begin{array}{l}12.3 \pm \\
4.3 \text { years }\end{array}$ & $\begin{array}{l}13.0 \pm \\
4.3 \text { years }\end{array}$ & \\
\hline Established smoking & $1.7 \%$ & $0.9 \%$ & $2.4 \%$ & $<0.01$ \\
\hline Current smoking & $3.2 \%$ & $1.9 \%$ & $4.2 \%$ & $<0.01$ \\
\hline Intention to smoke & $2.7 \%$ & $1.7 \%$ & $3.5 \%$ & $<0.01$ \\
\hline Never-smoker & $79.3 \%$ & $81.0 \%$ & $78.0 \%$ & $<0.01$ \\
\hline \multicolumn{5}{|l|}{ Smoking environment (\%) } \\
\hline Father smokes & $72.0 \%$ & $75.7 \%$ & $69.1 \%$ & $<0.01$ \\
\hline Mother smokes & $4.4 \%$ & $4.4 \%$ & $4.4 \%$ & $=0.96$ \\
\hline Teacher smokes & $37.3 \%$ & $41.8 \%$ & $33.7 \%$ & $<0.01$ \\
\hline \multicolumn{5}{|l|}{ Attitude towards female smokers (\%) } \\
\hline Appears cool & $8.4 \%$ & $7.5 \%$ & $9.1 \%$ & $<0.01$ \\
\hline Appears independent & $19.3 \%$ & $17.9 \%$ & $20.3 \%$ & $<0.01$ \\
\hline Appears charismatic & $7.5 \%$ & $5.8 \%$ & $8.9 \%$ & $<0.01$ \\
\hline \multicolumn{5}{|l|}{ Knowledge regarding CMFW (\%) } \\
\hline Heard of CMFW & $68.6 \%$ & $61.3 \%$ & $74.5 \%$ & $<0.01$ \\
\hline Seen CMFW & $45.2 \%$ & $34.2 \%$ & $54.0 \%$ & $<0.01$ \\
\hline Tried CMFW & $7.2 \%$ & $4.1 \%$ & $9.6 \%$ & $<0.01$ \\
\hline \multicolumn{5}{|l|}{ Health risk knowledge (\%) } \\
\hline $\begin{array}{l}\text { Believe smoking is very } \\
\text { harmful }\end{array}$ & $86.8 \%$ & $87.8 \%$ & $86.0 \%$ & $=0.09$ \\
\hline $\begin{array}{l}\text { Believe smoking increases } \\
\text { risk of CV disease }\end{array}$ & $65.1 \%$ & $62.2 \%$ & $67.5 \%$ & $<0.01$ \\
\hline $\begin{array}{l}\text { Believe smoking increases } \\
\text { risk of lung cancer }\end{array}$ & $95.7 \%$ & $94.5 \%$ & $96.6 \%$ & $<0.01$ \\
\hline $\begin{array}{l}\text { Believe smoking increases } \\
\text { risk of hepatitis }\end{array}$ & $69.3 \%$ & $71.2 \%$ & $67.7 \%$ & $<0.01$ \\
\hline \multicolumn{5}{|l|}{ Obtain smoke health risk information via (\%) } \\
\hline Parents & $53.0 \%$ & $51.5 \%$ & $54.2 \%$ & $<0.01$ \\
\hline Doctor & $49.7 \%$ & $49.7 \%$ & $49.7 \%$ & $=0.97$ \\
\hline Television & $76.7 \%$ & $74.2 \%$ & $78.7 \%$ & $<0.01$ \\
\hline Internet & $55.0 \%$ & $49.6 \%$ & $59.4 \%$ & $<0.01$ \\
\hline \multicolumn{5}{|c|}{ Knowledge and attitudes towards China anti-tobacco policies (\%) } \\
\hline $\begin{array}{l}\text { Knowledge of anti-minor } \\
\text { tobacco sale law }\end{array}$ & $70.9 \%$ & $69.6 \%$ & $72.0 \%$ & $<0.01$ \\
\hline $\begin{array}{l}\text { Support of anti-minor } \\
\text { tobacco sale law }\end{array}$ & $72.6 \%$ & $74.1 \%$ & $71.5 \%$ & $<0.01$ \\
\hline $\begin{array}{l}\text { Support of anti-tobacco advertisement } \\
\text { law }\end{array}$ & $58.2 \%$ & $61.6 \%$ & $55.5 \%$ & $<0.01$ \\
\hline
\end{tabular}

*by $\chi^{2}$ test.

CMFW, cigarettes made for women; CV, cardiovascular; RFS, rural female students; UFS, urban female students.

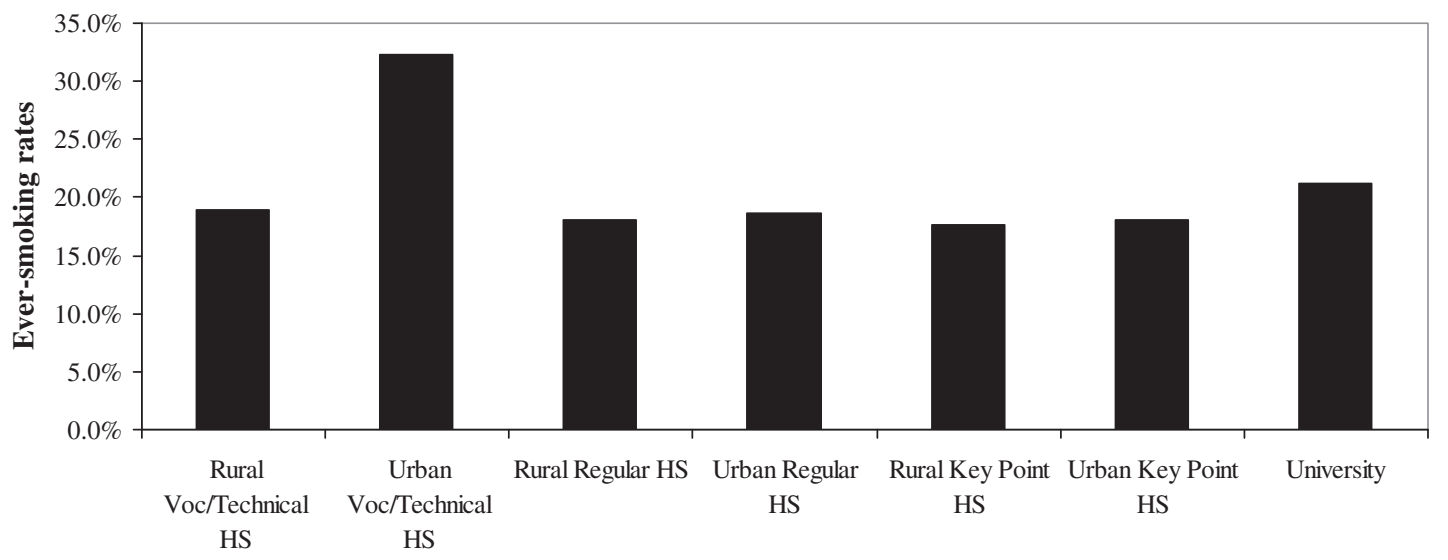

School Classification

Figure 1 Ever-smoking rates by rural and urban school classification, China 2008. 
Table 5 Correlates of ES among young Chinese women attending schools in 6 provinces, $2008(n=11095)$

\begin{tabular}{|c|c|c|}
\hline Correlate & p Value* & $\mathrm{OR} \dagger(95 \% \mathrm{CI})$ \\
\hline \multicolumn{3}{|l|}{ Region } \\
\hline Urban & $<0.01$ & $0.84(0.75$ to 0.94$)$ \\
\hline Rural & & 1.00 \\
\hline \multicolumn{3}{|l|}{ Pocket money monthly (To nearest US\$) (\%) } \\
\hline Above $\$ 14$ & $<0.01$ & $1.35(1.20$ to 1.51$)$ \\
\hline Between 0-\$14 & & 1.00 \\
\hline \multicolumn{3}{|l|}{ Self-reported school performance } \\
\hline Very poor, poor & 0.01 & $1.50(1.20$ to 1.80$)$ \\
\hline Very good, good, fair & & 1.00 \\
\hline \multicolumn{3}{|l|}{ Friend smokes } \\
\hline Yes & $<0.01$ & $1.73(1.53$ to 1.95$)$ \\
\hline No & & 1.00 \\
\hline \multicolumn{3}{|l|}{ Boyfriend smokes } \\
\hline Yes & $<0.01$ & $1.63(1.40$ to 1.90$)$ \\
\hline Other (no, not applicable) & & 1.00 \\
\hline \multicolumn{3}{|l|}{ Parents reaction to smoking } \\
\hline Other (indifferent, happy, I don't know) & $<0.01$ & $1.63(1.41$ to 1.90$)$ \\
\hline Angry & & 1.00 \\
\hline \multicolumn{3}{|l|}{ Attitude towards female smoking } \\
\hline Other & $<0.01$ & $0.87(0.80$ to 1.00$)$ \\
\hline Seems to lack self-confidence & & 1.00 \\
\hline \multicolumn{3}{|l|}{ CMFW knowledge, attitudes, beliefs } \\
\hline \multicolumn{3}{|l|}{ Seen or heard of CMFW } \\
\hline Yes & $<0.01$ & $1.66(1.49$ to 1.86$)$ \\
\hline No & & 1.00 \\
\hline \multicolumn{3}{|l|}{ Think CMFW taste better } \\
\hline Yes & 0.23 & $1.10(0.93$ to 1.31$)$ \\
\hline Don't know & $<0.01$ & $0.52(0.44$ to 0.62$)$ \\
\hline No & & 1.00 \\
\hline \multicolumn{3}{|l|}{ Think CMFW less harmful to health } \\
\hline Yes & $<0.01$ & $1.54(1.33$ to 1.79$)$ \\
\hline Don't know & $<0.01$ & 1.31 (1.14 to 1.52$)$ \\
\hline No & & 1.00 \\
\hline \multicolumn{3}{|l|}{ Low refusal self-efficacy } \\
\hline Yes & $<0.01$ & 6.35 (5.32 to 7.57$)$ \\
\hline No & & 1.00 \\
\hline \multicolumn{3}{|l|}{ Believe smoking is very harmful } \\
\hline Yes & 0.04 & $0.42(0.22$ to 0.84$)$ \\
\hline Other & & 1.00 \\
\hline \multicolumn{3}{|l|}{ Attitude towards antismoking laws } \\
\hline Support restricted sales to minors & 0.57 & $1.02(0.89$ to 1.16$)$ \\
\hline Indifferent to restricted sales to minors & $<0.01$ & $1.61(1.30$ to 2.01$)$ \\
\hline Oppose restricted sales to minors & & 1.00 \\
\hline
\end{tabular}

*Bivariate analysis, by $\chi^{2}$ test.

†Based on multivariate logistic analysis.

$\ddagger$ Low refusal self-efficacy=subject would smoke a cigarette if offered by best friend.

CMFW, cigarettes made for women; ES, ever-smoking.

$\mathrm{p}=0.1$ level in the bivariate analysis, significant associations for ES were shown for higher pocket money availability, poor selfreported school performance, friend smoking, boyfriend smoking, parents non-angry reaction to smoking, positive attitude towards female smoking, seen or heard of CMFW, a belief that CMFW are less harmful, low refusal self-efficacy and indifference to a law that prohibits sales of cigarettes to minors. Interestingly, urban residence status was slightly protective against ES (OR 0.84, 95\% CI 0.75 to 0.94 ). Low-refusal self-efficacy had the strongest effect (OR $6.35,95 \%$ CI 5.32 to 7.57 ) on ES.

\section{DISCUSSION}

Our findings suggest that the proportion of young women students, aged 14-24years, who have experimented with smoking in China now makes up roughly one-fifth of the total female student population. This level of experimentation is an ominous harbinger for a potentially devastating tobacco-related disease epidemic within a previously unaffected population.

This is the first large-scale study to confirm that having seen or heard of women's cigarette brands (CMFW) predicts smoking experimentation among young women in China. Most CMFW are manufactured by TTCs, although there are now brands manufactured by the China Tobacco Corporation (the State monopoly) that target women. We previously found that urban female high school and college students in China had exposure to CMFW and marketing directed at women. Urbanisation and the feminine mystique portrayed in such advertisements and promotions compound the increased risk for smoking initiation created by low-refusal self-efficacy. Low-refusal self-efficacy may also facilitate smoking initiation through acceptance of cigarettes as a traditional Chinese gesture of good will. In addition, the China Seven Cities study has found that psychological intent to exhibit autonomy, to regulate mood, to control weight and to make friends have been reasons for adolescents to begin to smoke. ${ }^{17}$ Urbanisation and economic growth can add to these psychological conditions risks among young women.

There appears to be hope and concern regarding smoking knowledge among young women in that so many respondents had reasonable awareness of the health risks associated with smoking; many, however, have misunderstandings about cardiovascular disease risks, which is a finding consistent with previous studies. ${ }^{3}$ The need for more accurate information on health risks is suggested by the high percentage of respondents in our study who thought smoking causes hepatitis. In addition, television appears to be a significant source of information for three-quarters of our respondents. Effective televised anti-tobacco messages that debunk the value of CMFW might then be indicated as a tobacco control intervention. Unfortunately, our study predated the widespread use of telephone-based social networking systems, but it would be of interest to consider this information channel in future research among young Chinese women.

Urbanisation is part of the rapid economic growth occurring in China, along with double digit gross national product expansion in each of the last 10 years (slowing in 2008 with the global economic recession). ${ }^{18} 19$ However, our findings suggest that focusing tobacco prevention efforts among women in rural and urban areas is indicated. Nonetheless, urban vocational/ technical school students appear to be at higher risk than students in other school settings, and future prevention and intervention programs could focus on this particular demographic group.

Our study is limited by the cross-sectional design, which describes a single point in time. As such, we are unable to determine if the associations we found are actual predictors of smoking. In addition, we did not include non-students, which is a significant proportion $(>50 \%)$ of the entire female Chinese population. In fact, one study among migrant commercial sex workers suggests that ever-smoking may be as high as $54.9 \%$ within this group. ${ }^{12}$

Although, we enjoyed a high (94.9\%) participation rate, the non-responders in our study were students who opted out of the study or students who did not attend class that day (ie, sick, doctor's appointment, etc). These students may have poorer academic performance and higher risk for smoking initiation. Although we stressed to students that participation in the study was voluntary, some students may have answered questions according to what they thought authorities wanted to hear because the surveys were conducted in classrooms. 


\section{What this paper adds}

Ever-smoking rates among young women students in rural and urban areas in China are rising.

- Urbanisation and westernisation seen as a result of China's rapidly expanding may be creating susceptibility to smoking within this vulnerable population.

- However, little detailed behavioural information on young Chinese women has been reported to date, and more specific data on what may influence young Chinese women to initiate smoking under these scenarios are needed.

Nevertheless, our findings suggest that smoking experimentation among young women in China is rising and that targeted marketing strategies are being implemented by the TTCs and China Tobacco Corporation to capture this lucrative and vulnerable market. Public health professionals, health providers, teachers and parents need to be aware of this dynamic situation in order to prevent a tobacco-related disease disaster from affecting young women in China. The world is watching as China assumes an economic leadership role as to how it will treat its young women. Will it allow them to become the next source of tobacco-related disease statistics, or will it protect them from the strategies already proved to be effective in recruiting women in the Western world? Women in China have already come a long way, and they do not need western or other cigarettes made especially for them to succeed in this journey.

Acknowledgements This study was supported by National Institute of Health, National Cancer Institute Grant Number R03-CA130728. The authors are especially grateful to the six provincial CDC senior public health officials who acted as team survey leaders to help us implement the field work: Yi Yang (Guangdong Pharmaceutical University, School of Public Health), Xihe Yu (Jilin University, School of Public Health), Yibing Fan (Nanchang Municipal Center for Disease Prevention and Control), Guohong Qian (Gansu Provincial Institute for Health Education) and Xin Guo (Beijing Municipal Center for Disease Prevention and Control). The authors are also very grateful to the following students and colleagues at UCSF and PUMC who contributed their efforts to this project: Pamela Ling, Stanton Glantz, Karen Finch and Mei Cuizhu. The authors are also grateful to Dr Danny Sam and Dr Rakesh Chaudhary at Kaiser Permanente Santa Clara for their flexibility with the participation of MGH during his internal medicine residency.
Funding NIH.

Competing interests None.

Ethics approval This study was conducted with the approval of the University of California, San Francisco.

Provenance and peer review Not commissioned; externally peer reviewed.

\section{REFERENCES}

1. WHO. Report on the global tobacco epidemic, 2008: the MPOWER package. Geneva: World Health Organization, 2008.

2. Mackay J, Eriksen M, Shafey 0. The tobacco atlas 2nd edn. Atlanta (GA): American Cancer Society, 2006. 1106-7.

3. Yang G, Fan L, Tan J, et al. Smoking in China: findings of the 1996 national prevalence survey. JAMA 1999:282:1247-53.

4. Novotny TE. The "ultimate prize" for big tobacco: opening the Chinese cigarette market by cigarette smuggling. PLoS Med 2006; 3:e228.

5. Johnson CA, Palmer PH, Chou CP, et al. Tobacco use among youth and adults in Mainland China: the China seven cities study. Public Health 2006;120:1156-69.

6. Yang G, Ma J, Chen AP, et al. Smoking among adolescents in China: 1998 survey findings. Int J Epidemiol 2004;33:1103-10.

7. Ma $\mathbf{H}$, Unger JB, Chou CP, et al. Risk factors for adolescent smoking in urban and rural China: findings from the China seven cities study. Addict Behav 2008; $33: 1081-5$

8. National Bureau of Statistics People's Republic of China. Major figures of the 2000 population census. http://www.stats.gov.cn/was40/reldetail.jsp? docid $=402459940$ (accessed 1 Apr 2009)

9. Zhou Q, Lin Y. China's urbanization encounters "urban disease". China News. 2005; 14:33. http://www.chinanews.cn.

10. Ho MG, Shi Y, Ma S, et al. Perceptions of tobacco advertising and marketing that might lead to smoking initiation among Chinese high school girls. Tob Control 2007:16:359-60.

11. Chinese Academy of Preventive Medicine. National Prevalence Survey of smoking patterns. Smoking and Health in China, 1996.

12. Department of Planning, Chinese Ministry of Education. Report of Education Statistics Volume 1 No. 26, February 27, 2003. http://www.moe.edu.cn/english/ planning s.htm (accessed 1 Apr 2009).

13. Finch K, Ma SJ, Qin D, et al. Smoking knowledge attitudes and behaviors among rural-to-urban migrant women in Beijing, China. Asia Pac J Public Health. DOI:10.1177/1010539509335034.

14. MacFarquhar R, Schoenhals M. Mao's last revolution. Cambridge, Massachusetts, USA: The Belknap Press/Harvard University Press, 2006. 153-68.

15. Guo Q, Johnson CA, Unger JB, et al. Utility of the theory of reasoned action and theory of planned behavior for predicting Chinese adolescent smoking. Addict Behav 2007:32:1066-81.

16. WHO. The revised Global Burden of Disease report (GBD) 2002 estimates. http:// www.who.int/healthinfo/global_burden_disease/estimates_regional_2002_revised/ en/print.html, (accessed 8 Aug 2009).

17. Weiss JW, Spruijt-Metz D, Palmer PH, et al. China Seven Cities Study Research Team. Smoking among adolescents in China: an analysis based upon the meanings of smoking theory. Am J Health Promot 2006;20:171-8.

18. Pan Z. Socioeconomic predictors of smoking and smoking frequency in urban China: Evidence of smoking as a social function. Health Promot Int 2004;19:309-15.

19. National Bureau of Statistics of China. China Statistical Yearbook 2008. http:// www.stats.gov.cn/english/statisticaldata/yearlydata/ (accessed 1 Apr 2009). 